\title{
Cotidiano escolar e (des)respeito: o que dizem os livros de ocorrência escolar
}

\section{School quotidian and (dis)respect: what the school occurrence books} say

\author{
Elisiane Spencer Quevedo Goethel* \\ Universidade Estadual Paulista Júlio de Mesquita Filho \\ Priscila Carla Cardoso** \\ Universidade Estadual Paulista Júlio de Mesquita Filho \\ Débora Cristina Fonseca*** \\ Universidade Estadual Paulista Júlio de Mesquita Filho
}

Resumo Este artigo tem como objetivo discutir como o respeito e desrespeito aparecem no cotidiano escolar e são significados nas falas e nos registros dos educadores. Para tanto, foram analisados dados coletados nos Livros de Ocorrência Escolar (LOE). Trata-se de uma pesquisa documental de análise qualitativa, onde utilizou-se a técnica de análise de conteúdo. A discussão teve como aporte teórico a teoria históricocultural. $\mathrm{O}$ estudo aponta a necessidade da compreensão de como se dá a construção do respeito por parte daqueles que atuam no ambiente escolar, bem como seu importante papel nesse processo, sem deixar de levar em consideração questões como cultura, autoridade e comprometimento com a garantia ao acesso do conhecimento.

PALAVRAS-CHAVE: Livro de ocorrência escolar; Respeito; Desrespeito; Cotidiano escolar.

Abstract This article aims to discuss how respect and disrespect appear in school quotidian and are signified in the speeches and in the registers of educators. For that, data collected in the School Occurrence Books (LOE) were analyzed. This is a documentary research of qualitative analysis, where the technique of content analysis was used. The discussion had as theoretical contribution the historical-cultural theory. The study points out the need to understand how the construction of respect by those who work in the school environment takes place, as well as its important role in this process, while taking into account issues such as culture, authority and commitment to guarantee access of knowledge.

KEYWORDS: School's occurrence books/occurrence books; Respect; Disrespect; School quotidian. 


\section{Introdução}

A questão do respeito/desrespeito tem sido um tema recorrente nas falas e nos registros dos educadores quando se trata de estudos que investigam a violência no âmbito escolar. Se considerarmos que a instituição escola está inserida dentro de um modo de produção capitalista, que possui como uma das suas características a desigualdade social, podemos analisar como a relação professor aluno é mediada por pressupostos sociais e históricos de lugar de mundo. Esses pressupostos, por sua vez, refletem diretamente no ambiente escolar, uma vez que crianças, adolescentes e professores são afetados por seu contexto histórico-cultural, trazendo em sua formação as contradições e conflitos dessa estrutura social. O mesmo pode ser considerado em relação aos sentidos e significados construídos historicamente sobre o ser aluno e ser professor, pouco ancorados nas condições concretas do cotidiano escolar, principalmente após a Constituição de 1988 e a LDB de 1996, que tornaram a educação um direito de todos e dever do estado. Por estes mecanismos, muitas crianças e adolescentes que antes não frequentavam a instituição escolar, passaram a estar cotidianamente, não correspondendo às expectativas do "ser aluno" esperado pela instituição.

A dificuldade parece estar na discrepância entre a realidade escolar e as expectativas dos professores. As escolas esperam alunos ideais e o que recebem são indivíduos com diferentes trajetórias e experiências de vida oriundas de formas de se relacionar produzidas pelas novas tecnologias, mercados de consumo, grupos culturais e religiosos característicos da sociedade, que reivindicam, da sua forma o direito a escuta e argumentação. Sobre isso Fortuna (2006, p. 89) afirma: "mais que descumprir regras, a indisciplina pode significar um rico manancial de informações sobre como os alunos vivem a escola e seus conteúdos". É nesse sentido que Vigotski (2003) ao discorrer sobre o desenvolvimento da moralidade defende que as relações desrespeitosas têm a ver com insuficiência na educação moral do indivíduo e não com desvio de comportamento.

Para Soares (2012) o professor, muitas vezes, encontra-se dissociado e apartado da contemporaneidade, não por uma escolha consciente, mas pelas atividades cotidianas alienantes. Assim acaba por se envolver nas atividades sem que possa refletir sobre elas, o que acaba por ofuscar as potencialidades necessárias para avaliação crítica da realidade no cotidiano escolar. Entretanto vale ressaltar que este distanciamento crítico não significa indiferença, mas sim a percepção fragmentada da realidade escolar complexa.

Dentre os principais aspectos apontados pelos professores como falta de respeito estão às relações agressivas, incluindo tanto agressão física como verbal; irresponsabilidade diante dos compromissos escolares; dispersão devido ao uso de aparelhos eletrônicos em sala de aula; formas diferentes de se vestir que não o uso de uniforme, entre outros (DAYRELL E CARRANO, 2014).

De imediato podemos notar que em um ambiente de diversidades como a escola as concepções de respeito/desrespeito podem ter muitos significados. Segundo Vigotski (1934) a cultura e o contexto histórico onde está inserido o sujeito têm 
influência sobre o seu sentido e significado acerca do que é respeito. Assim, uma atitude respeitosa ou desrespeitosa para um sujeito, pode não ser para outro, já que suas vivências de determinadas situações são diferentes, tendo em vista sua constituição ativa, social e histórica (SOUZA, 2004). Tanto é assim que embora muito presente nas anotações feitas nos Livros de Ocorrências Escolar, as palavras respeito e desrespeito são normalmente associadas a um leque diverso de comportamentos que vão desde a inadequação até atos violentos ou de indisciplina.

Ainda deve se levar em consideração que a questão do (des)respeito está intrinsecamente associada à autoridade do professor. Para Fortuna (2006), é a partir da "perda do controle" que surge às relações de poder estabelecidas dentro de uma escola, o que faz pensar sobre a legitimidade da autoridade do professor entre os alunos.

Portanto, procurando entender melhor o significado destas palavras constantemente utilizadas pelos educadores, esse artigo tem como objetivo discutir como respeito e desrespeito aparecem no cotidiano escolar e são significados nos dados coletados nos Livros de Ocorrência Escolar (LOE).

\section{Metodologia}

O trabalho tem como referencial a pesquisa qualitativa, utilizando como instrumento de coleta de dados a análise documental. Os dados foram sistematizados através da análise de conteúdo que, segundo Bardin (2006), permite ir além do visível para descoberta da realidade que se insere no fenômeno.

Este artigo se apoia em dados levantados nos Livros de Ocorrência Escolar de uma escola estadual do interior do estado de São Paulo. A escola em questão está localizada em um bairro de periferia, e contava com 361 e 383 alunos matriculados, respectivamente nos anos de 2012 e 2013.

Concentramo-nos na análise de $23 \mathrm{LOE}$, que compreenderam do $6^{\circ}$ ano do ensino fundamental a $1^{\text {a }}$ série do ensino médio. Foram mapeados e identificados todos os registros que continham as palavras respeito e/ou desrespeito, sendo encontradas 52 ocorrências registradas.

Para tanto, com a finalidade de desenvolver a análise e discussão, os dados foram agrupados em unidades temáticas: palavrão, autoridade, insulto, gritar, agressão física, deboche, gesto obsceno, apelido, normas da escola, sem especificação (somente a utilização da palavra respeito e/ou desrespeito, sem a atribuição a alguma ação). As quatro unidades que tiveram maior número de registros, foram: sem especificação, palavrão, autoridade e normas da escola. Estas unidades temáticas deram origem as categorias: Respeito e Cultura, Respeito e Autoridade, e, Respeito e Regras.

Embora muito presente nos discursos dos professores e na sociedade em geral, encontramos dificuldades em definir o que é (des)respeito nos registros por eles efetuados nos LOEs. Parece não haver clareza quando se trata do assunto em questão, bem como uma diversidade de concepções. Mesmo com um número significativo de ocorrências que se utiliza das palavras respeito/desrespeito, em sua grande maioria, os registros não deixam claro o que elas significam. Exemplos: 
O aluno foi advertido e conscientizado da importância do respeito ao professor (registro 1).

Foi mal-educado com a professora, não tem respeito (registro 2).

Aluno desrespeitou a professora e jogou apostila no colega (registro 3).

Notamos que os termos respeito/desrespeito são utilizados a partir da significação construída pelo professor, sem nenhuma explanação do ocorrido, impossibilitando a compreensão do contexto e ou conflito estabelecido. Isto nos coloca a refletir se o aluno envolvido na situação partilha da mesma significação e compreende o que o professor está nomeando como respeito/desrespeito. O registro parece ser feito apenas para constar no LOE, uma vez que não há preocupação dos professores em esclarecer a informação prestada. Essa ação vai ao encontro do que diz Ratto (2007), quando a autora afirma que os livros de ocorrência parecem estar comprometidos com uma lógica voltada para a obediência, à docilidade e a conformação, sem que haja qualquer intuito pedagógico de resolução de conflitos. É notório que o ato de registrar é mais importante do que a informação prestada, uma vez que na maioria das ocorrências não há registros de providências tomadas.

Ainda, no caso desses registros, se considerarmos que em determinado momento podem se constituir como prova ou como um instrumento de defesa do professor diante de questionamentos dos alunos, seus familiares ou até mesmo da justiça, a não explicitação do contexto pode distorcer a realidade, haja vista que apenas a versão do professor é que consta no LOE. Segundo Chrispino e Chrispino (2008), há uma tendência à judicialização das relações escolares e a consequente responsabilização civil dos educadores. Neste aspecto, o registro constitui-se como um instrumento de defesa do professor, no caso de um processo judicial ou mesmo explicações aos responsáveis sobre o histórico de comportamentos do aluno na escola, justificando ações como a transferência compulsória para outra escola, haja vista que após a Constituição Federal de 1998 e leis complementares (LDB, ECA) não é mais possível a expulsão do aluno.

Também foi possível constatar a diversidade de concepções entre os discursos dos professores sobre o que se considera respeito/desrespeito. Sobre isso, na perspectiva histórico-cultural podemos entender que ainda que existam os valores tidos como universais, sendo o respeito parte deles, o significado social pode variar dependendo do contexto em que o sujeito está inserido. Mais do que isso, cada indivíduo separadamente, pode vivenciar e atribuir um sentido pessoal a esse valor moral. Isso significa dizer que os sentidos e significados do que é considerado respeito/desrespeito terá forte influência dos modos de vida e das relações sociais que cada indivíduo estabelece (VIGOTSKY, 2001).

Porém, vale ressaltar que embora os sentidos tenham um caráter singular, estes são construídos por meio das apropriações de experiências sociais, assim, a relação dialética entre singular-coletivo nunca deve ser desconsiderada, pois apesar dos sentidos serem da ordem do privado são configurados a partir do contexto social e podem ser modificados dependendo das experiências do sujeito. 
Não podemos deixar de pontuar que o ambiente escolar é "um espaço aberto a vida não escolar", que muitas vezes é apropriado e reelaborado também pelos alunos que lá convivem e buscam reconhecimento interpessoal (DAYRELL, 2007, p. 1120). Se pensarmos com Martucelli (2000), a influência dos alunos no ambiente escolar faz com que o que era modelado unicamente pelos critérios da sociabilidade adulta, e vê adentrar novas influências e modelos, operando com lógicas e critérios próprios, como os de justiça e autoridade, que podem entrar em choque com os existentes na escola.

É por esse caráter mutável e dinâmico que a escola possui dificuldades em lidar com questões relacionadas ao desrespeito, sendo que os conflitos escolares, muitas vezes, se dão por diferenças de sentidos e significados do que é considerado respeito pelas diferentes culturas e gerações presentes na comunidade escolar (SOUZA, 2004).

\section{Respeito e cultura}

$\mathrm{Na}$ perspectiva histórico-cultural, os valores, as crenças e as ideologias são construídos socialmente, por meio da relação dialética que o indivíduo estabelece com o meio em que vive, sendo assim, sofrerão influências da cultura e do momento histórico, pois, cada cultura e período histórico estabelecem atos como morais ou não, ou seja, o que é moral nesse momento histórico pode não ser em outro, daí a importância do social na construção dos valores (VIGOTSKI, 1997). Isso ficou constatado já que a segunda maior frequência de registros relacionados ao tema respeito/desrespeito tinha como eixo principal a questão da pronúncia de palavrão e/ou palavras de baixo calão:

Chamei sua atenção para que ela parasse e ela me ofendeu me falando um palavrão. Não tem nenhum respeito pela professora (registro 4).

$\mathrm{O}$ aluno foi inconveniente, faltando com o respeito com a sala e com a professora, utilizando palavrões (registro 5).

Não tem respeito com a professora, ofendendo-a com palavrões (registro 6).

Percebe-se que os professores entendem a pronuncia de palavrões e/ou palavras de baixo calão como um desrespeito, principalmente quando dirigidos a eles. Isso pode ser devido à construção do que seja respeito/desrespeito dentro de um determinado momento e contexto social, não correspondendo à mesma construção social e histórica dos alunos, ou seja, no seu contexto social pode não ter sido estabelecido que pronunciar determinadas palavras seja falta de respeito para com o próximo. Zaluar (1992) e Santos (2002) argumentam que há um desencontro entre a instituição escolar e as particularidades culturais dos alunos que dela fazem parte. Santos (2002) ainda acrescenta que essa relação é marcada por uma violência simbólica do saber da escola, que muitas vezes é enviesado por hábitos sociais dos professores e funcionários da instituição, havendo uma relação de poder que impõe um conjunto de valores aos alunos sem um processo de construção conjunta.

Isso não significa dizer que os alunos devam pronunciar palavras de baixo calão inadvertidamente por fazer parte das suas particularidades culturais. Ao contrário, a escola como um importante meio de socialização e acesso ao conhecimento tem a função de construir juntamente com eles a compreensão social de determinados 
termos, problematizando o seu uso em diferentes contextos. Desta forma, entendemos que a escola pode desenvolver seu papel socializador, potencializando os alunos a utilização de vocabulários novos, o que pode implicar na reconstrução de valores humanos no trato com o outro. Contudo, tal ação se torna quase impossível num modelo de escola que entende seu papel como apenas transmissora do conhecimento formal presente na grade curricular. Para Santos "[...] a escola parece relutar em alcançar um relacionamento capaz de incorporar demandas diferenciadas e distintas da matriz disciplinar oficial da instituição escolar”(2002 p. 128).

Embora se suponha que ocorra essa diferença de construção de significações e sentidos devido à cultura e gerações, na pesquisa não foi possível comprová-la devido a ausência de registro da versão do aluno sobre o ocorrido, o que aponta para o caráter inquisitorial que os livros de ocorrência têm assumido nos ambientes escolares, assemelhando-se aos processos judiciais, uma vez que apenas as versões dos professores, gestores e funcionários são consideradas, salvo algumas exceções em que é relatada a versão do aluno, porém escrita por um professor, coordenador e/ou diretor. Barbosa (2012), já apontava para essa relação unilateral ao constatar que embora haja um desrespeito mútuo entre professores e alunos ainda prevalece, nas ocorrências registradas pela escola, apenas o desrespeito do aluno com relação ao professor. Para a autora a atribuição ao aluno do desrespeito a priori acaba por naturalizar como intrínseco ao sujeito algo que é construído nas e pelas relações sociais e que dependerá do contexto e do momento histórico vivido.

\section{Respeito e Autoridade}

Toda relação de respeito implica em presença de autoridade. Para Barbosa (2012) a autoridade é comumente confundida como algo que resulte em obediência, até mesmo por via da violência seja ela física e/ou verbal. Essa relação entre autoridade e obediência teve destaque nos registros dos professores:

Estava jogando giz pela classe. Não respeitou a ordem para parar (registro 7).

O aluno foi colocado para fora da sala, depois de várias advertências verbais para ficar quieto e fazer a lição. Só ficou resmungando e não me respeitou (registro 8).

O aluno tem atitudes grosseiras de falta de respeito e descumprimento de ordem em relação ao mapeamento. Faz de tudo para irritar a professora e não faz as atividades conforme solicitado (registro 9).

É perceptível nos trechos apresentados a compreensão da autoridade como estritamente ligada ao ato de obedecer. Nesse caso, o que se entende por autoridade produz relações desiguais de humilhação e inferioridade de uma das partes envolvidas na situação, no caso o aluno que, por sua vez, responde reativamente a essa ordem autoritária. Arendt (2011, p.129) lembra que "[...] se autoridade deve ser definida de alguma forma, deve sê-lo, então, tanto em contraposição à coerção pela força como à 
persuasão através dos argumentos". Assim, Arendt (2011) entende a autoridade não como algo dado a priori, mas sim como algo construído nas relações sociais, a partir da legitimação da figura de autoridade pelo grupo, que a reconhece como tal. Esse processo por sua vez acontece por meio da admiração, sendo o afeto um aspecto preponderante nessa relação dialética entre respeito e autoridade.

É nesse sentido que Souza (2004) argumenta que se aqueles que atuam no ambiente escolar não são respeitados, deve ser porque os alunos não os consideram como autoridade. Isso pode ser verificado nos trechos a seguir:

O aluno fica saindo o tempo todo do lugar, mexe com todos da sala, provocando o tempo todo e quando solicitado que se sente, responde ao professor com todo desrespeito (registro 10).

Aluno não faz atividades, fica o tempo todo conversando. Estava respondendo de forma mal-educada para a professora e desafiando sua autoridade, não tem respeito (registro 11).

Percebe-se a invalidação da autoridade por meio de ações como não acatar a ordem dada pelo professor, responder de forma considerada grosseira, entre outros. Os registros revelam que embora os professores, os funcionários e os gestores ocupem a posição de autoridade, esta não é legitimada por um grupo considerável de alunos. Para Arendt (2011) o reconhecimento legitimado é o pressuposto para que o professor exerça a autoridade no contexto escolar. Segundo Juarez Dayrell:

Se antes a autoridade do professor era legitimada pelo papel que ocupava, constituindo-se no principal ator nas visões clássicas de socialização, atualmente é o professor que precisa construir sua própria legitimidade entre os jovens (DAYRELL, 2014, p.307).

Por confundirem o conceito de autoridade com o de chefia, ou seja, "[...] aquele que a autoridade não induz ao respeito, mas consegue obediência pelo medo do seu poder" (SCHILLING, 2008, p.696), muitos professores acabam por assumir posições autoritárias, usando de forma indevida o termo autoridade para camuflar o exercício de poder indiscriminado e não mais para exercer suas funções educativas. Também há aqueles que, por receio se assumir essa postura, se abstém de ocupar o lugar de autoridade. É por isso que Dussel e Caruso (2003) apontam para necessidade de se pensar em uma autoridade democrática em que tenha como pressuposto a construção de certa ordem, sempre aberta à crítica e a transformação. $O$ desafio é pensar nesse paradoxo - autoridade e liberdade - sem que haja subordinação da segunda e que também não se desfaça a primeira.

Outro aspecto a ser considerado nesta relação são as diferenças de sentidos e significados do que se considera respeito/desrespeito tanto por professores como para alunos. É perceptível, pelos registros dos professores, que o não acatar ordem é considerado uma atitude desrespeitosa. Tanto é assim que as descrições de tais ações são frequentemente precedidas pelas palavras: "falta de respeito", "desrespeito", "não tem respeito", podendo não corresponder ao sentido e significado apropriado pelos alunos, não os remetendo, portanto, a algo ruim ou negativo. Ou ainda, o questiona- 
mento de ordens naturalizado no contexto extramuros da escola e na relação com os amigos, implica na forma de se comportar na escola.

Nesse sentido, a escola assume um papel de fundamental importância na construção coletiva de relações respeitosas. Isso implica dizer que as ressignificações deverão acontecer dialeticamente na relação professor-aluno, não só o que o aluno considera respeito/desrespeito deverá sofrer modificações nessa perspectiva, mas também as concepções trazidas pelos professores. Cada grupo pode construir coletivamente os entendimentos de respeito e desrespeito no cotidiano escolar.

\section{Respeito e regras}

O homem, ao produzir sua existência revela a historicidade, a ideologia, as relações sociais e até mesmo o modo de produção vigente. Por isso não há como entender o sujeito sem entender o contexto social em que vive, uma vez que a relação indivíduo-sociedade é de mediação, na qual um constitui o outro dialeticamente (OZELLA \& AGUIAR, 2008). Assim, o respeito deve ser entendido como um valor moral que é experienciado e apropriado nas relações sociais. Para tanto, o respeito a regras estabelecidas pela escola deve ser algo construído coletivamente a fim de que haja sentido para o grupo de alunos que a ela pertence. E mais do que isso, a participação é o único caminho para construção de uma formação democrática que vise o exercício da cidadania. Mas, para se falar em participação é necessário levar em consideração dois princípios básicos: a formação teórica para vida cidadã que envolve a aprendizagem de valores, conteúdos históricos da democracia, entre outros e a criação de espaços para experimentação do exercício da participação democrática.

$\mathrm{Na}$ escola em questão, segundo informações obtidas por meio de funcionários da instituição, o conjunto de regras era entregue por escrito para os responsáveis no ato da matrícula, ou seja, aos alunos eram impostas todas as normas que a equipe gestora, juntamente com o corpo docente entendiam como importantes e necessárias, sem ter a garantia do conhecimento, compreensão e concordância dos alunos. A participação dos alunos nesse processo era inexiste. Parece haver por parte da escola o pressuposto de que todos são conhecedores de tais regras e a elas devem se subordinar. Tal procedimento impositivo reflete-se nos trechos a seguir:

Novamente não respeitou as regras e normas da escola. Por várias vezes pedi para que entrasse na classe e fizesse a lição. A aluna não respeitou a professora e saiu correndo pelo corredor juntamente com o aluno "X". Na verdade, ela queria ficar no pátio com o pessoal que está grafitando a escola. Ultimamente essa aluna resiste muito em seguir as regras da escola, desrespeita a todos e é muito irônica (registro 12).

Não retornou à sala no horário após o intervalo. Os alunos já haviam sido avisados quanto às punições pelo desrespeito as regras (registro 13).

A resistência dos alunos em não respeitar as regras estabelecidas pode vir do sentimento de não pertencimento ao processo que resultou nesses acordos que lhe foram impostos. Segundo Ratto (2007), as normas da escola estão muito mais atrela- 
das à normalização - medidas voltadas para a formatação homogeneizante, destinadas a sujeição de modelos preestabelecidos - do que à normatização, que se refere a certo ordenamento que possibilita a participação ativa do sujeito e consequentemente a vida coletiva. Sobre essa perspectiva, podemos dizer que a escola pesquisada, segue a lógica da normalização, uma vez que sujeita os alunos a um conjunto de regras das quais, muitas vezes, não se sentem pertencentes.

É possível que práticas que visem à discussão e a construção coletiva de aspectos ligados a organização do ambiente escolar não sejam bem recebidas pelo corpo docente, configurando-se como uma ameaça à sua autoridade. Diferente dessa percepção, entendemos que a experiência participativa permite que os alunos vivenciem valores importantes como solidariedade e democracia, assim, possam respeitar, perceber e reconhecer o outro com suas diferenças (DAYRELL E CARRANO, 2014). Mas para isso, Santos (2002) aponta a necessidade do diálogo e até mesmo do conflito para que as dificuldades sejam sanadas e, assim, se estabeleçam relações escolares respeitosas:

[...] a violência surge como a afirmação do silêncio e de um enclausuramento do gesto e da palavra. Para se poder afirmar o discurso do diálogo impõe-se, portanto, não somente o fortalecimento das instituições escolares e a afirmação do espaço social multicultural, como o reconhecimento do conflito como potencialmente criador de laços sociais. Dessa forma, é condição fundamental que se exerça a negociação enquanto estratégia de resolução de conflitos na instituição escolar (SANTOS, 2012, P.122).

Nesta perspectiva Soares (2012) defende que o exercício da autoridade do professor deve pautar-se pelo diálogo que, por sua vez, mobiliza o saber e o pensar e não no silenciar do aluno. Para o autor, a autoridade do professor se legitima a partir da sua capacidade de mobilizar no outro o desejo de aprender algo e isso se faz por meio do diálogo. Nessa mesma lógica de pensamento Dayrell e Carrano (2014) defendem que a capacidade de escuta e argumentação são dois recursos imprescindíveis num ambiente escolar, já que a maioria dos conflitos entre professor-aluno diz respeito às dificuldades de comunicação decorrente de significações dos fatos de forma diferente.

Barbosa (2012) destacou alguns aspectos que entendeu como fundamentais para o estabelecimento de relações respeitosas no ambiente escolar, os quais corroboram, entre eles: investimento na escuta e na fala, de modo que as manifestações de pontos de vistas, singularidades e saberes sejam garantidas por todos (professores, funcionários e alunos); concepção do sujeito como ser autônomo; instituição de autoridade (e não de autoritarismo); comprometimento com a educação a fim de garantir o acesso ao conhecimento em suas formas mais desenvolvidas.

\section{Considerações finais}

A análise dos registros sobre respeito e desrespeito presentes nos Livros de Ocorrência Escolar de uma escola pública do interior paulista ficou evidente que um número significativo de registros não explícita o entendimento do termo por parte de professore(a)s, funcionário(a)s e gestores. Foi possível identificar ainda, três temáticas categorizadas como: Respeito e Cultura; Respeito e Autoridade; Respeito e Regras.. 
Em todas elas, evidenciou-se um aspecto em comum: a dificuldade da escola em (re) construir conjuntamente com os alunos relações respeitosas. A falta de diálogo para melhor compreensão do contexto social que o aluno vive faz com que os professores considerem situações de conflitos escolares como um ato de desrespeito a priori, sendo significado como um comportamento intencional contra a autoridade docente. Dayrell e Carrano (2014) defendem que a escola bem como aqueles que dela fazem parte necessitam ter conhecimento das trajetórias não escolares de seus alunos, suas experiências e o tempo e espaços por meio dos quais constroem suas histórias de vida.

Além disso, ficou constatado que duas das categorias de maior frequência, "Respeito e Autoridade" e "Respeito e Regras", estão relacionadas à questão da obediência de uma determinada ordem, ainda que tenham como foco aspectos distintos. Isso significa dizer que o termo respeito parece associado à manutenção e controle da ordem no ambiente escolar, imposta por uma significação de que os alunos devem saber e corresponder a esta ordem vigente no âmbito escolar. Sendo assim, o respeito não é visto como um sentimento construído social e historicamente e significado na experiência de vida de cada sujeito. Nesta perspectiva, quando os alunos não correspondem a expectativa de comportamento respeitável, desejado pela escola, esses são tomados como indisciplinados e violentos. Pensamos que a escola não tem conseguido trabalhar na perspectiva de construção coletiva dos elementos presentes no cotidiano da escola, representado por diferentes significados e sentidos.

Com base nestes dados, pensamos que uma ação coletiva, construindo o entendimento de cada grupo sobre o que seja respeito e desrespeito pode fomentar o desenvolvimento e a emancipação dos sujeitos alunos e professores/gestores.

É necessário que aqueles que atuam no ambiente escolar compreendam como se dá a construção do entendimento do que se considera respeito, bem como seu importante papel nesse processo, sem deixar de levar em consideração questões como cultura, autoridade e comprometimento com a garantia de acesso ao conhecimento. Portanto, a escola tem o desafio de promover, por meio de processos educativos, questionamentos e reflexões críticas sobre a realidade, com o intuito de ressignificar e configurar novos sentidos para valores morais, como respeito, de forma a proporcionar o desenvolvimento humano nas suas máximas potencialidades e estabelecer relações saudáveis, que não por meio da violência, quer seja, física ou simbólica.

Ainda não se deve desconsiderar a burocratização que se faz bastante presente na escola. Para Soares (2012) esse processo faz com que a escola perca o seu real sentido e assuma o papel meramente de máquina escolar burocrática, destituída de qualquer autoridade. Os professores e funcionários ficam indiferentes, muitas vezes, aos rumos da escola como uma instituição pública e aos seus próprios trabalhos.

Assim, é necessário e importante que se faça uma análise crítica da realidade educacional, mas também que se tenha claro os limites postos por um sistema que visa à manutenção da ordem social e não a construção de uma educação que promova uma sociedade mais justa e promotora do desenvolvimento humano. 


\section{Referências}

BARBOSA, E. T. Os sentidos do respeito na escola: uma análise da perspectiva da psicologia histórico-cultural. 2012.177 p. Dissertação (Mestrado em Psicologia) - Pontifícia Universidade Católica de Campinas, Campinas, 2012.

BARDIN, L. Análise de Conteúdo. 3. Ed. Lisboa: Edições 70, 2006.

CHRISPINO, A.; CHRISPINO, R. S. A Judicialização das Relações Escolares e a Responsabilidade Civil dos Educadores. Ensaio: avaliação de políticas públicas em educação, v. 16, n.58, p. 9-30, jan/mar. 2008.

DAYRELL, J. A escola "faz" as juventudes? Reflexões em torno da socialização juvenil. In: Educ. Soc.[online]. Campinas, vol. 28, n. 100 - Especial, p. 1105-1128, out. 2007. Disponível em $<$ http://www.cedes.unicamp.br/>

DAYRELL, J. Juventude, Socialização e Escola. In: DAYRELL, J.; CARRANO, P.; MAIA, C. L. (Org.). Juventude e ensino médio: sujeitos e currículos em diálogo. Belo Horizonte: Universidade Federal de Minas Gerais, 2014. p. 298-322.

DAYRELL, J.; CARRANO, P. Juventude e Ensino Médio: quem é esse aluno que chega à escola. In: DAYRELL, J.; CARRANO, P.; MAIA, C. L. (Org.). Juventude e ensino médio: sujeitos e currículos em diálogo. Belo Horizonte: Universidade Federal de Minas Gerais, 2014 p. $101-133$.

FORTUNA, T. R. Indisciplina escolar: da compreensão à intervenção. In: Xavier, M. L. (Org.). Disciplina escolar: enfrentamentos e reflexões. 2. ed. Porto Alegre, RS: Mediação, 2006

MARTUCCELLI, D. La fabricacion des individus à l'ecole. In: VAN ZANTEN, A. L'ecole: l'etat des savoirs. Paris: La Decourvete, 2000, p. 421- 442.

OZELLA, S., \& AGUIAR, W. M. J. Desmistificando a concepção de adolescência. Cadernos de Pesquisa, v. 38, n.133, p. 97-125, jan/abr. 2008.

RATTO, A. L. S. Livros de ocorrência: (in) disciplina, normalização e subjetivação. São Paulo: Cortez, 2007.

SANTOS, J. V. T. A violência na escola, uma questão social global. In: BRICEÑO-LEÓN, R. (Org.). Violencia, sociedad y justicia en América Latina. Buenos Aires: Consejo Latinoamericano de Ciencias Sociales, 2001, p. 117-133.

SOARES, A. S. A autoridade do professor e a função da escola. Educação \& Realidade, v. 37, n. 3, p. 841-861, set/dez. 2012.

SOUZA, V. L. T. As interações na escola e seus significados e sentidos na formação de valores. 2004. p. 227 Tese (Doutorado em Educação) - Pontifícia Universidade Católica de São Paulo, São Paulo, 2004.

VYGOTSKI, L.V. (1997). La Moral Insanity. In: Obras Ecogidas V (PP. 165-169). Madrid: Visor. (Original publicado em 1934).

VIGOTSKI, L. V. Psicologia Pedagógica. Porto Alegre: Artmed, 2003

VIGOTSKY, L. S. A Construção do Pensamento e Linguagem. São Paulo: Martins Fontes, 2001.

VYGOTSKI, L. S. La Moral Insanity. In: VYGOTSKI, Lev Semenovitch. Obras Escogidas V. Madri: Visor, 1997. p. 165-169.

ZALUAR, A. Violência e educação. São Paulo: Cortez, 1992. 
* Doutoranda do Programa de Pós-graduação em Educação da Universidade Estadual Paulista Júlio de Mesquita Filho, Rio Claro, São Paulo, Brasil.

* Mestranda em Educação pela Universidade Estadual Paulista Júlio de Mesquita Filho, Rio Claro, São Paulo, Brasil.

*** Professora doutora da Universidade Estadual Paulista Júlio de Mesquita Filho, Rio Claro, São Paulo, Brasil.

\section{Correspondência}

Debora Cristina Fonseca - Universidade Estadual Paulista Júlio de Mesquita Filho, Instituto de Biociências de Rio Claro, Departamento de Educação. Avenida 24 A, 1515. Bela Vista. CEP: 13506-900. Rio Claro, São Paulo, Brasil.

E-mail: lisispencer@gmail.com - priscilacarlacardoso@gmail.com - deboracf@rc.unesp.br

Recebido em 23 de outubro de 2016

Aprovado em 10 de maio de 2017 